\title{
Rheological properties of synthetic mucus for airway clearance
}

\author{
O. Lafforgue ${ }^{1}$, I. Seyssiecq ${ }^{1}$, S. Poncet ${ }^{1,2}$, J. Favier $^{1}$ \\ ${ }^{1}$ Aix-Marseille Université, CNRS, Ecole Centrale de Marseille, Laboratoire M2P2 UMR 7340 \\ 38 rue F. Joliot-Curie, Technopôle de Château-Gombert, 13451 Marseille, France \\ ${ }^{2}$ Université de Sherbrooke, Faculté de génie, Département de génie mécanique \\ 2500 Boulevard de l'Université, Sherbrooke (QC) JIK 2Rl, Canada
}

\begin{abstract}
In this work, a complete rheological characterization of bronchial mucus simulants based on the composition proposed by Zahm et al. [1] is presented. Dynamic Small Amplitude Oscillatory Shear (SAOS) experiments, Steady State (SS) flow measurements and three Intervals Thixotropy Tests (3ITT), are carried out to investigate the global rheological complexities of simulants (viscoelasticity, viscoplasticity, shear - thinning and thixotropy) as a function of scleroglucan concentrations $(0.5$ to $2 \mathrm{wt} \%)$ and under temperatures of 20 and 37 ${ }^{\circ} \mathrm{C}$. SAOS measurements show that the limit of the linear viscoelastic range as well as the elasticity both increase with increasing sclerogucan concentrations. Depending on the sollicitation frequency, the $0.5 \mathrm{wt} \%$ gel response is either liquid-like or solid-like, whereas more concentrated gels show a solid-like response over the whole frequency range. The temperature dependence of gels response is negligible in the $20-37^{\circ} \mathrm{C}$ range. The HerschelBulkley (HB) model is chosen to fit the SS flow curve of simulants. The evolution of HB parameters versus polymer concentration show that both shear-thinning and viscoplasticity increase with increasing concentrations. 3ITTs allow calculation of recovery thixotropic times after shearings at $100 \mathrm{~s}^{-1}$ or $1.6 \mathrm{~s}^{-1}$. Empiric correlations are proposed to quantify the effect of polymer concentration on rheological parameters of mucus simulants.
\end{abstract}

KEYWORDS: synthetic bronchial mucus; viscoelasticity, viscoplasticity, shear - thinning, thixotropy 


\section{INTRODUCTION}

A large number of fluids in human body, such as blood or mucus, produced by different organs, are known to exhibit complex non Newtonian rheological properties under physiological states. When transported in the airways as a result of cough or cilia beating, bronchial mucus is characterized by a non constant, shear rate and time dependent viscosity, in both normal and pathological conditions. Bronchial mucus is mainly composed of water (90-95\%), mucins (2-5\%), lipids (1-2\%), salts (1\%), $0.02 \%$ of DNA and other molecules such as cells debris [2]. Mucins are high molecular weight glycoproteins insuring a structural protection function. The entangled and cross-linked network of its branched chains forms a 3D matrix spanning the mucus gel layer [3]. As a consequence of this complex internal structure, bronchial mucus is a non Newtonian fluid displaying all the possible rheological complexities such as viscoplasticity, shear-thinning, viscoelasticity and thixotropy. All these properties directly affect the way mucus flows and, as a consequence, the vital clearance function of the mucus layer coating the airways. The mechanism of mucus clearance can be described by the following two steps:

Step 1: inhaled particles or pathogens are trapped inside the mucus gel where enzymes and antibodies can biochemically disrupt them.

Step 2 : mucus is mainly transported by the mucociliary mechanism or by cough towards the pharynx where it is either expectorated or digested.

It is however known that, under certain disease conditions such as Cystic Fibrosis (CF), the clearance function is affected by modifications of the mucus composition and consequently, of its viscosity. Due to a lack of hydration (in the case of $\mathrm{CF}$ ), mucus can indeed become very thick and difficulties may arise to properly evacuate this fluid from the airways where it can accumulate and become more easily infected. A good understanding of mucus rheology is 
thus of prime importance in order to develop new care solutions for patients suffering from $\mathrm{CF}$ or other chronic respiratory diseases. Among possible care solutions, clearance helping devices, based on different technologies, have been developed during the last decades. These small devices can be used by patients at home, on a daily basis to increase the volume of mucus expectoration and limit the need for respiratory physiotherapy. As an example, a newly developed apparatus known as the Simeox ${ }^{\circledR}$, imposes an oscillatory air depression to the air flow during the exhalation phase of the patient. Based on the thixotropic and shear-thinning nature of mucus, such a solicitation induces a decrease of its viscosity and stimulates its expectoration. More insight into the rheology of respiratory mucus is needed to further improve the efficiency of such clearance helping devices. Although there is a large number of studies devoted to the rheological characterization of certain types of mucus, the results are still difficult to interpret, due to the use of different rheological techniques, but also due to the time evolution (aging) of such biological materials [4]. Furthermore, variations in the method used to collect samples (contamination issues), together with the natural variability (depending on the patient, the pathology, the occurence of an infection...) of this complex biological fluid lead to important discrepancies in the existing literature, concerning the results on mucus rheological characterization [5]. Numerous previous works devoted to the study of mucus rheology (either synthetic or native mucus from different organs), have only described part of its rheological properties. For instance, many works have used dynamic oscillatory shear measurements to characterize mucus rheology $[6 ; 7 ; 8 ; 9 ; 10 ; 11 ; 12]$. Under small deformations (SAOS) these measurements mostly reflect the properties of mucus under its native, unperturbed state and are useful to describe the linear viscoelastic response of mucus. On the contrary, in other works, the authors have made the choice to characterize mucus rheology using only continuous shear experiments $[1 ; 13 ; 14 ; 15]$. In these cases, the measured properties mostly reflect the flow behavior of mucus and can be used to investigate 
its viscosity under physiological shearing rates prevailing in human lungs during normal functioning or during temporary events such as cough. Even in studies where both dynamic oscillatory and shear flow measurements were carried out, the thixotropic nature of mucus was not accounted for $[5 ; 16 ; 17 ; 18 ; 19 ; 20 ; 21]$, or at least not on a quantitative point of view $[22 ; 23 ; 24]$. As a consequence, a complete and intrinsically consistent characterization campaign is still missing in the open literature. As the use of real mucus implies strong issues related to available quantities, and rises questions about the impact of the collection method on the fluid composition, the choice made in this work is to use mucus simulants. In this context, this work proposes a rheological characterization of mucus simulants at different active polymer concentrations ( 0.5 to $2 \%$ ), under a temperature of 20 or $37^{\circ} \mathrm{C}$ allowing to cover the range of air physiological temperature along the airways and using a broad range of available rheological tests (SAOS, controlled shear stress SS flow tests and 3ITT). In an attempt to quantify the measured properties, empirical equations are used to represent the evolution of different rheological parameters as a function of the active polymer concentration.

\section{MATERIALS AND METHODS}

\section{Preparation of mucus simulants}

The composition and preparation of polymeric synthetic solutions used to mimic human bronchial mucus are described in Zahm et al. [1]. To account for the natural variability of real mucus from one patient to another but also depending on health conditions, gels with different scleroglucan $\left(\right.$ Actigum $^{\mathrm{TM}}$ ) concentrations ranging from 0.5 to $2 \mathrm{wt} \%$ were prepared. Mucus simulants are aqueous solutions mainly composed of two types of polymers, Viscogum ${ }^{\mathrm{TM}} \mathrm{FA}$ $\left(\right.$ Cargill $\left.{ }^{\mathrm{TM}}\right)$ and Actigum ${ }^{\mathrm{TM}}$ CS 6 (Cargill $\left.{ }^{\mathrm{TM}}\right)$. The polymers used in this work were kindly provided by the Laserson compagny (Etampes, France). Viscogum ${ }^{\mathrm{TM}} \mathrm{FA}$ is a galactomannan 
gum extracted from locust beans and Actigum ${ }^{\mathrm{TM}}$ CS 6 is a scleroglucan (branched homopolysaccharide). It consists in a glucose chain branched every three units by an additional glucose forming a three dimensional (triple helix) structure. Sodium chloride $(99.8+\% \mathrm{NaCl})$ and di-sodium tetraborate 10aq $\left(99.5+\% \mathrm{Na}_{2} \mathrm{~B}_{4} \mathrm{O}_{7} \cdot 10 \mathrm{H}_{2} \mathrm{O}\right)$ were purchased from Chem-Lab NV (Zedelgem, Belgium). Distilled water used in all preparations was produced using a 2012 distillator (GFL, France). Mucus simulants solutions were prepared within glass bottles filled with $200 \mathrm{mg}$ of distilled water. Then, $0.9 \mathrm{wt} \%$ of $\mathrm{NaCl}, 0.5 \mathrm{wt} \%$ of Viscogum $^{\mathrm{TM}} \mathrm{FA}$ and a chosen fraction (ranging from $0.5 \mathrm{wt} \%$ to $2 \mathrm{wt} \%$ ) of Actigum ${ }^{\mathrm{TM}} \mathrm{CS} 6$ were successively added into the solution under magnetic stirring (Ikamag® RET) at room temperature. The mixture was kept under agitation for $48 \mathrm{~h}$ at room temperature. After this time period, a mass corresponding to $4 \mathrm{~mL}$ of di-sodium tetraborate at $0.02 \mathrm{M}$ was added. This addition induces the cross-linking of the polymeric chains, building a 3D gel matrix that mimicks the mucin network responsible for the internal structure of real mucus. The agitation is kept for a few more hours before storing the final mixture at $4^{\circ} \mathrm{C}$. Before performing the measurements, the solution is fractionnated into several $30 \mathrm{~mL}$ plastic vials and then allowed to recover at room temperature. Such mucus simulants were found to mimic accurately the main properties of bronchial mucus in the case of different pathologies.

\section{Rheological measurements}

\section{Rheometers and measuring systems}

Rheological measurements were performed using two controlled-stress rheometers, the AR 550 and the DHR-2 (TA Instruments) equiped with a measuring system consisting of a $2^{\circ}$ stainless steel cone $(40 \mathrm{~mm}$ or $50 \mathrm{~mm}$ in diameter). The temperature was controlled by a Peltier plate. A wet steel lid or a thin silicone oil layer insuring a water saturated atmosphere around the sample was used as a dehydration preventing solution. 


\section{Sample loading}

A small amount of gel was loaded onto the Peltier plate by gently pouring it from the vial in order to minimize shear history effects. The geometry was then lowered down to the corresponding gap plus a few micrometers and the excess of fluid was removed on the edges, the exact gap value was then set. The desired temperature $\left(20^{\circ} \mathrm{C}\right.$ or $\left.37^{\circ} \mathrm{C}\right)$ was also set before the tests began.

\section{Measurements protocoles}

Viscoelastic properties of the simulants were investigated through a series of dynamic shear experiments (Small Amplitude Oscillatory Shear: SAOS). The results were interpreted based on the evolution of the elastic and viscous moduli $\left(\mathrm{G}^{\prime}, \mathrm{G}^{\prime \prime}\right)$ and the loss angle $(\delta)$ as a function of the sinusoidal input. The stress dependency of the different gels $(0.5 \mathrm{wt} \%$ to $2 \mathrm{wt} \%$ in active polymer) response was first measured via stress amplitude sweeps at constant frequency $\left(\frac{1}{2 \pi} \mathrm{Hz}\right)$. This is a classical test carried out in order to determine, for each solution, the limit of the Linear ViscoElastic (LVE) range. The frequency dependency (in a maximum range of $10^{-5}$ to $100 \mathrm{~Hz}$ ) of the different gels response was also measured at constant stress amplitude, within the LVE range according to the stress amplitude sweep results. The temperature dependency of simulants rehological properties was finally investigated by comparing stress amplitude sweeps obtained for a given sample at either $20^{\circ} \mathrm{C}$ (ambiant air temperature) or $37^{\circ} \mathrm{C}$ (physiological temperature in the lower airways). However, to fully characterize the behavior of a mucus layer in response to in vivo solicitations such as cough or air flows artificially induced by clearance helping devices, the rheological measurements have to be performed far beyond the LVE range. Rotational controlled shear stress flow tests were then used to determine the rheological properties of the mucus simulants under shear flow conditions. In order to quantify the viscoplastic and the shear-thinning effects independently 
of the thixotropic ones, steady state rheograms were recorded. Such a steady state curve is obtained by applying a given shear stress until the corresponding shear rate reaches a constant value. Steady state (SS) flow curves of the different simulants were modelized using a 3 parameters Herschel-Bulkley (HB) model. This model accounts for the fluid viscoplasticity via the yield stress value $\left(\tau_{0 \mathrm{HB}}\right)$ and for its shear - thinning behavior via the flow $(\mathrm{n})$ and consistency $(\mathrm{K})$ indexes values. The thixotropy of the more concentrated mucus simulant was separately quantified using three Intervals Thixotropy Tests (3ITT). A 3ITT test consists in a stepwise change of stress or strain rate to successively monitor the initial structure, then its breaking up and finally its recovery. More precisely, the 3ITTs applied here can be described as follows:

First interval: the sample is submitted to very low shear conditions $\left(\dot{\gamma}=0.029 s^{-1}\right)$. This interval gives a reference for the fluid structure "at rest" or at least under very low shear.

Second interval: higher shear conditions are imposed by applying a constant shear stress or shear rate to disrupt the internal structure until a steady state is reached (depending on the chosen stress or strain rate value). In our case, a constant shear rate value of either $1.6 \mathrm{~s}^{-1}$ or $100 \mathrm{~s}^{-1}$ was applied during step 2 , in order to submit the sample to shearing conditions representative of either normal shearing conditions in the airways, or during peculiar events such as cough.

Third interval: the sample is allowed to recover under very low shear conditions again $\left(\dot{\gamma}=0.029 s^{-1}\right)$. A time scale characterizing a given state of regeneration (chosen here at $90 \%$ and $100 \%$ of recovery based on the initial structure measured during step 1.) can then be calculated. 


\section{RESULTS}

\section{SAOS tests}

Stress amplitude and frequency sweep tests conducted at a constant temperature of $20^{\circ} \mathrm{C}$, on simulant gels at different Actigum ${ }^{\mathrm{TM}}$ concentrations, all display the same feature. An example is given in figure 1 for a $1.5 \mathrm{wt} \%$ Actigum $^{\mathrm{TM}}$ gel (figure 1 (a) stress amplitude sweep, (b) frequency sweep). A value of the elastic modulus $G^{\prime}$ above the viscous modulus $G^{\prime \prime}$ implies that the elastic behavior dominates the viscous one and indicates a solid-like or gel-like behavior, while $\mathrm{G}^{\prime \prime}>\mathrm{G}^{\prime}$ indicates a liquid-like behavior. In figure 1 (a), the stress amplitude value for which the transition from one behavior to the other is observed, is denoted by $\tau_{\mathrm{f}}$ (flow point value corresponding to the crossover of moduli $\mathrm{G}^{\prime}=\mathrm{G}^{\prime \prime}, \tan (\delta)=1$ ) and will be discussed hereafter. As a consequence, in the case of figure 1.(b) for which $\tau=1 \mathrm{~Pa}<\tau_{\mathrm{f}}$, the mucus simulant shows a gel-like behavior for all frequencies ranging from $10^{-3}$ to $10 \mathrm{~Hz}$. In the case of figure 1.(a), under a constant frequency of $\frac{1}{2 \pi} \mathrm{Hz}$, the two domains are successively observed, with a solid-like behavior for $\tau<\tau_{\mathrm{f}}$, then liquid-like behavior for $\tau>$ $\tau_{\mathrm{f}}$

\section{Stress amplitude sweep tests}

The stress amplitude dependency of the different gels response was recorded via stress amplitude sweeps at a constant frequency $\left(\frac{1}{2 \pi} \mathrm{Hz}\right)$ for all the concentrations in active polymer $(0.5 \mathrm{wt} \%$ to $2 \mathrm{wt} \%)$. The results obtained are displayed in figure 2 .

For all polymer concentrations, a plateau region for $\mathrm{G}^{\prime}$ and $\mathrm{G}^{\prime \prime}$ moduli defines the LVE Range at the preset frequency. A yield stress value $\left(\tau_{\mathrm{y}}\right)$ limits the LVE range and is determined from the end of the moduli plateau. Since the $G^{\prime}$ curve often deviates first from the plateau, the $G^{\prime}$ 
function is commonly chosen to determine $\tau_{\mathrm{y}}$. Here, a $10 \%$ deviation from the plateau has arbitrarily been set for $\tau_{\mathrm{y}}$ calculations. The yield stress is the stress limit below which no significant change of the internal structure occurs. For $\tau<\tau_{\mathrm{y}}$ the sample is displaying reversible viscoelastic behavior. On the contrary, above $\tau_{\mathrm{y}}$, the measurements no longer reflect the structure at rest due to early signs of stress induced microstructural evolutions. Based on the value of the yield stress and of the corresponding critical deformation $\gamma_{\mathrm{c}}$, one can also calculate the volumetric energy of cohesion of the $3 \mathrm{D}$ network $\mathrm{E}_{\mathrm{c}}$ in $\mathrm{J}_{\mathrm{m}} \mathrm{m}^{-3}$ (eq. (1)) [25]. This energy of cohesion can be used in a quantitative manner as a measure of the extent of intermolecular and intramolecular interactions of the polymeric internal structure [26].

$E_{c}=\frac{1}{2} \tau_{y} \cdot \gamma_{c}$

In the case of the mucus simulants tested here, it can be seen in figure 2 that above the critical yield stress, G' decreases while G" shows an overshoot before decreasing. This kind of behavior has been observed on lots of gels by Mezger [27] and is classified as a "Type III behavior or weak strain overshoot" by Hyun et al [28]. The flow point $\left(\tau_{\mathrm{f}}\right)$ is identified as the stress value for which a moduli crossover $\left(\mathrm{G}^{\prime}=\mathrm{G}^{\prime \prime}, \tan (\delta)=1\right)$ is observed. This flow point corresponds to the stress above which the material becomes more viscous than elastic due to critical microstructural breakdowns. Finally the stress corresponding to the maximum of G" (peak overshoot) is denote by $\tau_{\text {peak }}$ and is, for all concentrations, almost superimposed to the flow point stress (except for the $0.5 \mathrm{wt} \%$ gel for which the $\mathrm{G}^{\prime \prime}$ overshoot does not appear). The range between $\tau_{\mathrm{y}}$ and $\tau_{\mathrm{f}}$ is sometimes referred as the "yield zone" or the "yield / flow transition range" [27]. In this range, despite the predominance of elastic behavior $\left(G^{\prime}>G^{\prime \prime}\right)$, irreversible deformations might locally have already taken place. 
In the case of mucus simulants studied here, $\mathrm{G}^{\prime}$ and $\mathrm{G}^{\prime \prime}$ moduli plateau values, as well as yield, flow and peak stresses and volumetric cohesive energy, all show increasing values according to the Actigum ${ }^{\mathrm{TM}}$ concentration as reported in table 1 . The evolution with the Actigum $^{\mathrm{TM}}$ concentration of the different transition stresses $\left(\tau_{\mathrm{y}}, \tau_{\mathrm{f}}\right.$ and $\left.\tau_{\text {peak }}\right)$ as well as the volumetric energy of cohesion $\left(E_{c}\right)$ and the plateau moduli values are all displayed in figure 3 .

For quantification purposes, yield, flow and peak stresses variations with Actigum $^{\mathrm{TM}}$ concentration can be described by power law empirical relationships reported hereafter (equations $2 \& 3$ ). As previously mentioned, flow and peak stresses are almost superimposed, which makes sense since they both refer to the actual beginning of macroscopic flow of the gel ( $\mathrm{G}^{\prime \prime}>\mathrm{G}^{\prime}$ and friction starts decreasing). As a consequence a single empirical correlation is needed to account for the effect of polymer concentration on both flow and peak stresses. Equation 2 gives the quantitative evolution of the yield stress ( $\tau_{\mathrm{y}}$ in $\mathrm{Pa}$ ) as a function of Actigum $^{\mathrm{TM}}$ concentration $(\mathrm{C}$ in $\mathrm{wt} \%)$ :

$\tau_{y}=1.54 C^{2.31} \quad \mathrm{R}^{2}=0.981$

Equation 3 accounts for the Actigum ${ }^{\mathrm{TM}}$ dependency of both $\tau_{\mathrm{f}}$ and $\tau_{\text {peak }}$ :

$\tau_{f} \& \tau_{\text {peak }}=4.66 C^{1.68} \quad \mathrm{R}^{2}=0.990$

These evolutions are qualitatively compared to the evolution of the yield stress calculated from the HB modelling of the SS flow curve $\left(\tau_{0 \mathrm{HB}}\right)$ (see discussion part). Concerning $\mathrm{G}^{\prime}$ and G" plateau values (in Pa), they increase linearly (Figure 3(b)) with the active polymer concentration (in wt\%) with an average slope of 10 for G" and 49 for G'. The evolution of the volumetric energy of cohesion $\left(E_{c}\right.$ in $\left.\mathrm{J}^{-\mathrm{m}^{-3}}\right)$ of the $3 \mathrm{D}$ gel internal network versus the Actigum $^{\mathrm{TM}}$ concentration ( $\mathrm{C}$ in wt $\%$ ) is also a power law as reported in equation 4 : 
$E_{c}=0.076 C^{1.95} \quad \mathrm{R}^{2}=0.968$

\section{Temperature dependence of the $L V E$ range}

The temperature dependence of the LVE range of mucus simulants was measured by comparing stress amplitude sweeps obtained at either $20^{\circ} \mathrm{C}$ (ambient temperature) or $37^{\circ} \mathrm{C}$ (physiological temperature in the lower airways). This temperature range was chosen in accordance to the possible range of variation for the air at different stages of respiratory airways. Figure 4 presents the variations of elastic modulus and viscous modulus versus the stress amplitude for a constant frequency $\left(\frac{1}{2 \pi} \mathrm{Hz}\right)$ and a given Actigum ${ }^{\mathrm{TM}}$ concentration $(0.75 \mathrm{wt} \%)$ at either $20^{\circ} \mathrm{C}$ or $37^{\circ} \mathrm{C}$. Each curve is the average of 3 successive measurements. Measurements were also performed with simulants at different polymer concentrations and all display qualitatively identical results.

As it is observed in figure 4, the LVE range of the mucus simulant gel as well as the different stresses $\left(\tau_{\mathrm{y}}, \tau_{\mathrm{f}}, \tau_{\text {peak }}\right)$ characterizing the solid - liquid transition zone show very little dependence on the temperature in the $20-37^{\circ} \mathrm{C}$ range. The curves obtained at either 20 or $37^{\circ} \mathrm{C}$ are almost superimposed and the observed differences are of the same order of magnitude than reproducibility. Concerning the gels studied here, it can be concluded that the effect of temperature in the $20-37^{\circ} \mathrm{C}$ range on mucus simulants rheological properties is not significant compared to reproducibility.

\section{Frequency sweep tests}

Since the frequency is the inverse of a time, frequency sweep tests are usually performed in order to investigate the behavior of a substance as a function of the sollicitation characteristic time under small deformations. Short-term behavior of the sample is then simulated at high frequencies, whereas long-term behavior is displayed under low frequencies. The main 
concern under very low frequencies is the conservation of the sample during the important timelag needed to obtain these measuring points. So in these cases, a special care has to be taken to control samples dehydration. The frequency dependence of the mucus simulants response was measured by oscillating stress at increasing frequencies (maximun range: $10^{-5}$ to $100 \mathrm{~Hz}$ ) and a constant stress amplitude corresponding to a small deformation, i.e. within the LVE range $\left(\tau<\tau_{\mathrm{y}}\right)$ as measured at $\frac{1}{2 \pi} \mathrm{Hz}$ (see table 1.). Figure 5 gathers the evolutions of elastic modulus (a), viscous modulus (b) and loss angle (c) as a function of the applied frequency for the different Actigum ${ }^{\mathrm{TM}}$ concentrations.

Since working at very low frequencies implies a long experiment duration and, as a consequence, a more important risk of sample dehydration, all the simulants have been studied in the common range $10^{-2}$ to $10 \mathrm{~Hz}$. only in the case of the more diluted and the more concentrated gels, the frequency range was enlarged to $10^{-4}-10 \mathrm{~Hz}$ and $10^{-5}-10 \mathrm{~Hz}$ to investigate the possible occurence of a low frequency moduli crossover. Over the whole range of frequencies, simulants with Actigum ${ }^{\mathrm{TM}}$ concentrations ranging from $0.75 \mathrm{wt} \%$ to $2 \mathrm{wt} \%$, show a gel-like behavior characterized by an almost parallel low increase of $\mathrm{G}^{\prime}$ and $\mathrm{G}^{\prime \prime}$ (in $\log -\log$ scale) with $G^{\prime}$ values 2 to 7 times higher than G". Such a behavior is characteritic of a soft gel in which intermolecular forces are mostly responsible for the 3D internal network [27]. Therefore elastic behavior dominates the viscous one over the entire frequency range attesting for the gel stability. G' and G" only show a slight frequency dependence displaying an average slope in log-log representation of 0.1 in the case of $\mathrm{G}^{\prime}$ and 0.04 in the case of $\mathrm{G}^{\prime \prime}$ (see discussion part for interpretation).

The less concentrated simulant $(0.5 \mathrm{wt} \%)$ displays a different behavior. $\mathrm{G}^{\prime}$ and $\mathrm{G}^{\prime \prime}$ show a more important frequency dependence, especially under low frequencies due to a more 
flexible network. A moduli crossover (characterized by $\tan (\delta)=1$ in figure 5 (c)) is also observed at low frequencies $\left(<210^{-3} \mathrm{~Hz}\right)$ for which $\mathrm{G}^{\prime \prime}>\mathrm{G}^{\prime}$. Such a behavior corresponds to a liquid-like behavior and can be observed when a deformation (even very small) is applied at a sufficiently low rate (i.e. during a long time). On the contrary, an identical deformation applied at higher frequencies induces a solid-like response. The typical example usually given in rheology books to illustrate this behavior is the one of a silicone ball. Such a ball left at rest in a beaker for a long time will finally take the form of the beaker (viscous flow under low frequency or long time sollicitation), while the same ball thrown onto a wall will bounce, displaying an elastic behavior under high frequency or small time sollicitation. It is worth noting that the inverse of the frequency for the moduli crossover is sometimes used as a time characterizing the elasticity of the gel [29]. However, in this case, it would be delicate to interpret this value since complex internal structures composed of a large number of components with different lengths, flexibilities or mobilities, such as mucus simulants, are most likely to display viscoelastic properties governed by the superposition of several relaxation modes [2]. The low frequency crossover of moduli is not experimentally reached in the case of more concentrated simulants $(0.75 \mathrm{wt} \%$ to $2 \mathrm{wt} \%)$, for the range of tested frequencies. However, in figure $5(\mathrm{c}), \tan (\delta)$ increases when the frequency decreases, so that a moduli crossover would likely appear under sufficiently low frequency at a decreasing frequency value, as the concentration increases, traducing an increased elasticity for more concentrated mucus simulants.

\section{Steady-state (SS) flow test}

Steady state (SS) shear flow tests were performed on three successive samples at each Actigum $^{\mathrm{TM}}$ concentration. The response to the imposed stress $(\tau)$ is recorded in terms of steady state strain rate $(\dot{\gamma})$. The rheograms $(\tau(\dot{\gamma})$ curves) drawn as the average of the three 
measurements performed on each Actigum ${ }^{\mathrm{TM}}$ concentration displayed a similar shape for all polymer concentrations. Figure 6 shows an example of such a rheogram obtained in the case of a $2 \mathrm{wt} \%$ simulant.

A yield zone with a solid-like behavior $(\dot{\gamma} \rightarrow 0$ grey zone in figure 6$)$ is first observed until the progressive departure from a quasi vertical slope to the flow zone showing a shearthinning behavior (concave rheogram beyond the yield stress value) is reached. The yield zone is the manifestation of the yielding behavior of the gel structure that has already been characterized using SAOS stress amplitude sweeps tests. In SS flow mode, the transition between solid and liquid-like behaviors is defined by a stress value quoted $\tau_{0 \mathrm{HB}}$. This value is also referred in the literature as a yield stress but gives different values compared to the yield stress measured in SAOS mode (see discussion part). This is why a different notation $\left(\tau_{0 \mathrm{HB}}\right)$ is used to described this yield stress deduced from the fitting of SS flow experimental data by a 3 parameters Herschel-Bulkley model (equation 5) allowing to account for both the SS yield stress (viscoplastic behavior) and shear-thinning behavior.

$\tau=\tau_{0 H B}+K \dot{\gamma}^{n}$

where $\tau_{0 \mathrm{HB}}(\mathrm{Pa})$ is the SS flow yield stress, $\mathrm{K}\left(\mathrm{Pa} \cdot \mathrm{s}^{\mathrm{n}}\right)$ and $\mathrm{n}(-)$ are the consistency and flow indexes respectively deduced from the $\mathrm{HB}$ modelling. It is worth noting that, as SS flow curves (as well as the HB model) do not account for the time dependent flow behavior (thixotropy), the observed yield stress $\tau_{0 \mathrm{HB}}$ is not an inherent property of the material since the structural strength of the gel is shear history and thus time dependent.

The non Newtonian behavior observed in figure 6 , is the direct consequence, in the case of polymeric substances, of a shear-induced spatial structure transformation [30]. The HB model parameters obtained for the different polymer concentrations are reported in table 2 and 
account for the characterization of the steady-state flow behavior of simulants. The evolution of the different $\mathrm{HB}$ parameters with the Actigum ${ }^{\mathrm{TM}}$ concentration is drawn in figure 7 and clearly shows that both viscoplasticity (increase in $\tau_{0 \mathrm{HB}}$ value) and shear-thinning behavior (increase in $\mathrm{K}$, decrease in $\mathrm{n}$ ) increase as the active polymer concentration increases. In the case of the mucus simulants studied here, an attempt has been made to propose a quantification of the different measured rheological properties. Concerning data deduced from SS flow experiments, the evolution of HB parameters with the active polymer concentration (C in wt\%) can be quantified by the following empirical relationships (equations 6 to 8 ).

$\tau_{0 H B}=8.24 C^{1.34} \quad \mathrm{R}^{2}=0.99$

$K=0.315 C^{3.36} \quad \mathrm{R}^{2}=0.974$

$n=1-0.346 \mathrm{C} \quad \mathrm{R}^{2}=0.963$

Equation 6 accounts for the increase in viscoplasticity, whereas equations 7 and 8 account for the increase in shear-thinning behavior, as the active polymer concentration increases.

\section{Three Interval Thixotropy Tests}

3ITT tests were performed on the different simulant gels in order to investigate the thixotropic nature of mucus simulants independently of their SS flow behavior. Thixotropy is characteristic of complex internal structure systems and is linked to slow time evolutions in rheological properties due to either restructuring at rest or destructuring initiated by deformation [30]. Figure 8 represents a first 3ITT performed on a $2 \mathrm{wt} \%$ simulant. The second step imposes a shear flow under an effective shear rate of $1.6 \mathrm{~s}^{-1}$ corresponding to the order of magnitude of the shearing of a mucus layer in the tracheobronchial tree. Indeed, if the physiological maximum value for shear rate, can reached $10^{2}-10^{4} \mathrm{~s}^{-1}$ (for example during 
coughing), physiological rates in the normal lung are of the order of magnitude of 0.1 to $1 \mathrm{~s}^{-1}$. $[4 ; 8 ; 14]$. The three successive steps are plotted as apparent viscosity versus time.

After a shearing under $1.6 \mathrm{~s}^{-1}$ during step 2, one can observe in figure 8 that the thixotropic regeneration curve (step 3) allows the calculation of a thixotropic recovery time characterizing a given state of regeneration chosen here at $90 \%$ and $100 \%$ of recovery, based on the initial structure measured during step 1 . The thixotropic recovery time is, in this case of $2.7 \mathrm{~s}$ for $90 \%$ and $75 \mathrm{~s}$ for $100 \%$ of recovery.

Figure 9 gives the results of a second test also performed on a $2 \mathrm{wt} \%$ simulant. This time, the second step corresponds to a shear flow under a larger shear rate $\left(100 \mathrm{~s}^{-1}\right)$ matching the order of magnitude for the shearing of a mucus layer submitted to cough.

After a shearing at $100 \mathrm{~s}^{-1}$ during step 2 , one can observe in figure 9 that the thixotropic regeneration curve (step 3) gives a $90 \%$ recovery time of 17 s and a $100 \%$ recovery time of $917 \mathrm{~s}$, which are logically higher than the recovery times needed after the shearing under $1.6 \mathrm{~s}^{-1}$ observed in figure 8 .

\section{DISCUSSION}

During stress amplitude SAOS experiments (figure 2) a G" overshoot has been observed with mucus simulants. According to Hyun et al [28-31] or Mezger [27], such an overshoot is generally obtained in the case of cross-linked polymers or gel-like internal structures (existence of a 3D network). The overshoot is directly linked to the progressive collapse of the 3D network. During the initiation of flow, at first the friction increases due to spatial rearrangements of some free elements (for example relative motion of end pieces of chains). These irreversible motions induce an increase in dissipated energy ( $\mathrm{G}^{\prime \prime}$ increases). Then the breakdown of the internal superstructure occurs (at the $\tau_{\text {peak }}$ value) and the dissipated energy 
starts decreasing as the fluid actually flows. In the case of mucus simulants used in this work, the overshoot behavior shows a strong dependency on the Actigum ${ }^{\mathrm{TM}}$ concentration. On the one hand, the $\tau_{\text {peak }}$ value increases as the simulant concentration increases (figure 3(a) and eq. 3 for quantification). This is not surprising since more concentrated simulants have a stronger internal network that will need a higher energy input to collapse. On the other hand, the peak height is also increasing with the Actigum ${ }^{\mathrm{TM}}$ concentration (figure 2(b)). The overshoot amplitude is directly linked to the amount of friction occuring during the initiation of flow due to spatial rearrangements of free elements. A more concentrated sample is thus expected to dissipate more friction energy as a result of its higher network density (more cross-linking and chains entanglements). A G" overshoot during stress amplitude sweeps was rarely mentioned in the literature on the rheological characterization of mucus. In the work of Bastholm [9], a G" overshoot seems to occur with some of the tested cervical mucus samples, without any comment concerning this phenomenon. Celli et al. [5], performing a SAOS stress amplitude sweep on a sane gastric mucus sample (compared to a Helicobacter pylori contaminated one), also observed a "weak strain overshoot" on G" and refered to the work of Huyn et al. [28] for interpretation. Concerning now the internal network volumetric energy of cohesion $\mathrm{E}_{\mathrm{c}}$ values, we can refer to works by Mori et al. [32] or Niraula et al. [26] for comparison purposes. Based on SAOS characterizations on respectively biological suspensions or stabilized oil in water $(\mathrm{O} / \mathrm{W})$ emulsions both exhibiting a $3 \mathrm{D}$ cohesive network, they calculated the volumetric cohesive energy of the material internal network to account for the degree of interaction and thus of flocculation between droplets in the case of stabilized $\mathrm{O} / \mathrm{W}$ emulsions [26] and between bioflocs in the case of activated sludge suspensions [32]. The mucus simulants studied here are not flocculated suspensions nor liquid-liquid emulsions but aqueous dispersions of macromolecules. However since a 3D network exists both due to entanglement and cross-linking of the macromolecules the concept of volumetric cohesive energy can be 
useful to quantitatively account for the degree of interaction of the subsequent network. One can observe that the order of magnitude of $\mathrm{E}_{\mathrm{c}}$ for the Actigum ${ }^{\mathrm{TM}}$ based mucus simulants $(0.02$ to $0.36 \mathrm{~J} . \mathrm{m}^{-3}$ ) is intermediate between $\mathrm{E}_{\mathrm{c}}$ values calculated for biological activated sludge suspensions [32] $\left(0.2\right.$ to $\left.1.2 \mathrm{~J}^{-3} \mathrm{~m}^{-3}\right)$ and $\mathrm{E}_{\mathrm{c}}$ values of stabilized $\mathrm{O} / \mathrm{W}$ emulsions $\left(0.2410^{-3}\right.$ to $\left.2.9510^{-3} \mathrm{~J}_{\mathrm{m}}^{-3}\right)$. It is also worth noting that $\mathrm{E}_{\mathrm{c}}$ values showed important dependence upon the network macromolecular or suspended bioflocs concentration (power law (eq. 4) in this work, exponential law in [32]). The influence of the polymer concentration on stress amplitude SAOS measurements displayed in figure 3 for synthetic mucus, has been discussed in some previous works. As an example, Riley et al. [7] showed that an increase in polymer (Carbopol 934P) concentration induced an increase in both $\mathrm{G}^{\prime}$ and $\mathrm{G}^{\prime \prime}$ measured in the LVE range at a constant (5 Hz) frequency. Shah et al. [19] also observed working with mucus simulants that both $\mathrm{G}^{\prime}$ and $\mathrm{G}^{\prime \prime}$ (either measured at 1 or $100 \mathrm{rad} / \mathrm{s}$ ) increased with the coagulant concentration $(0.5,1.5$ and 3\%). Finally, Hamel \& Fiegel [10] measured an identical increase with crosslinked polymer concentration of $\mathrm{G}^{\prime}$ and $\mathrm{G}^{\prime \prime}$ moduli, performing on synthetic mucus strain sweeps at a constant frequency. Nevertheless, in all of these previous studies, the observed variations were not quantified. An interesting point that can however be pointed out is the fact that the achieved order of magnitude of $G^{\prime}$ and $G^{\prime \prime}$ (in the LVE range) with the mucus simulants tested in this work correspond to those usually observed with sane or pathologic native respiratory mucus. For instance, $\mathrm{CF}$ mucus can reach various viscoelasticity levels as a function of many factors. In the work of Dawson et al. [18] CF mucus displays viscoelastic properties, in terms of moduli plateau values, close to those displayed by the $2 \mathrm{wt} \%$ Actigum $^{\mathrm{TM}}$ gel while in the research of Yuan et al. [11], the measured behavior is close to the one measured with the $0.75 \mathrm{wt} \%$ gel. Concerning sane mucus, moduli plateau values close to those recorded with the $0.5 \mathrm{wt} \%$ solution have been observed [11]. Concerning the effect of temperature on the LVE range limit, identical results to those shown in figure 4 have been 
described for mucus gels with similar composition, in the same temperature range $(20,32$ or $36^{\circ} \mathrm{C}$ ) [33]. A very limited influence of temperature on simulants rheological properties measured both via stress amplitude sweeps and flow curves was recorded by the authors. Taylor et al. [6], who studied the rheological characterization of mucin - alginate gels, also reported no significant differences between the gels behaviors (frequency sweep tests) over a 10 to $60^{\circ} \mathrm{C}$ temperature range. The rheological properties of such aqueous polyoside solutions are known to be related to the conformation taken by the macromolecules (Viscogum ${ }^{\mathrm{TM}} \&$ Actigum $^{\mathrm{TM}}$ ). Mucus simulants studied here are composed of a constant amount of Viscogum $^{\mathrm{TM}}$ (galactomannan chains that are cross-linked in the presence of sodium tetraborate) and various proportions of Actigum ${ }^{\mathrm{TM}}$ (extracellular polyoside) that can adopt either a rigid helicoidal conformation or a random entangled conformation, as a function notably of temperature [29]. From the measurements displayed in figure 4, it can be concluded that Actigum ${ }^{\mathrm{TM}}$ molecules are likely to present the rigid helicoidal conformation in simulants tested here, leading to the observed gel-like behavior $\left(\mathrm{G}^{\prime}>\mathrm{G}^{\prime \prime}\right)$ and also that this conformation remains when the temperature is raised to values such as $37^{\circ} \mathrm{C}$.

During frequency SAOS sweeps, we obtained results (figure 5) that are, for 0.75 to $2 \mathrm{wt} \%$ gels, qualitatively comparable to those observed by Coussot et Grossiord [29] on a $0.5 \mathrm{wt} \%$ xanthan gum aqueous solution at $25^{\circ} \mathrm{C}$. Xanthan gum is an extracellular polyoside close to Actigum $^{\mathrm{TM}}$ in terms of macromolecular composition and structure (glucose chain branched every 2 units by other oside functions forming a 3D rigid double helix structure), exhibiting very similar rheological properties. The gel-like behavior of aqueous xanthan solutions over the whole frequency range is known to be linked to the helicoidal rigid conformation adopted by polyoside molecules under moderate temperatures or high ionic strength, impairing their ability to move under small sollicitations. In the case of Actigum ${ }^{\mathrm{TM}}$ aqueous solutions, 
Actigum $^{\mathrm{TM}}$ macromolecules are also known to adopt a rigid triple helix conformation (except under high temperatures or low ionic strength) that is responsible for the gel-like response measured over the entire range of tested frequencies in the case of $0.75 \mathrm{wt} \%$ to $2 \mathrm{wt} \%$ Actigum $^{\mathrm{TM}}$ gels. Kocevar-Nared et al. [23] also made observations qualitatively comparable to figure 5 in the case of rehydrated dried crude porcine gastric mucus. Varying the mucin concentration of rehydrated mucus, they observed that more concentrated samples displayed no moduli crossover (in the $0.1-100 \mathrm{~Hz}$ explored range) but a power law slight frequency dependence for both moduli whereas, more diluted sample displayed a stronger frequency dependence with a crossover point moving towards lower frequencies as the mucin concentration is increased and as the structure changes to gel-like. In the case of the $0.5 \mathrm{wt} \%$ gel studied here, the stronger dependence to the frequency can be linked to the increase in relative importance of Viscogum ${ }^{\mathrm{TM}}$ (flexible entangled network) compared to Actigum $^{\mathrm{TM}}$ (rigid network) in comparison to gels with higher Actigum ${ }^{\mathrm{TM}}$ concentrations.

During SS flow measurements, the concentration dependent yield stress and shear-thinning nature of mucus simulants has been observed (figure 6) and quantify (equations 6 to 8 ). Identical observations have already been reported but only qualitatively in the case of mucus simulants and native mucus based on measurements of their rheological flow behavior. The increase in viscoplasticity (yield stress) with the active polymer concentration has already been observed in the SAOS stress amplitude tests section of the paper. Yield stresses measured in flow mode $\tau_{0 \mathrm{HB}}$ show higher values than yield stresses measured in SAOS $\tau_{\mathrm{y}}$. This is not surprising since $\tau_{\mathrm{y}}$ corresponds to the end of the LVE range characterized by early motions of small elements of the complex internal polymeric structure (at the microscopic level), while $\tau_{0 \mathrm{HB}}$ corresponds to the proper beginning of flow measured at a macroscopic scale (existence of a finite shear rate in the measuring gap). It is also worth noting that both $\tau_{\mathrm{y}}$ 
and $\tau_{0 \mathrm{HB}}$ values are dependent on the calculation method (chosen $\%$ of deviation from the plateau for $\tau_{\mathrm{y}}$ and chosen limit value for $\dot{\gamma} \rightarrow 0$ in the case of $\left.\tau_{0 \mathrm{HB}}\right)$. As a consequence, both values should only be considered as order of magnitudes or for comparison purposes of data obtained using the same calculation method. As far as the evolution of yield stresses with the active concentration is concerned, Malkin et al. [34] reported the case of cysteine / Ag based colloidal gels for which the yield stress deduced from flow measurements decreases as the dilution factor of the initial gel increases, showing the decrease in strength of the rigid structure as the colloidal concentration decreases. If we now focus on the observed shearthinning properties of mucus simulants, Puchelle et al. [13] also described the shear-thinning nature of native and lyophilized pathological bronchial mucus but also of simulants composed of polyisobutylene solutions (3 and $6 \%$ in decalin). Measuring the SS flow curve of these gels, they obtained shear-thinning indexes (Ostwald de Waele or power law) matching the range observed in table 2 with our mucus simulants and varying from 0.44 to 0.64 . Banerjee et al. [14] also used a power law to describe the apparent viscosity of shear-thinning mucus simulants (tragacanth gum) mixed with different surfactants to evaluate their ability to reduce viscosity. They obtained viscosity reduction ratios varying from 1.5 to 7.2 depending on the type of surfactant under physiological shear rates $\left(0.1\right.$ to $1 \mathrm{~s}^{-1}$ in the tracheobronchial tree). The shear-thinning behavior of mammalian lung mucus is also cited by Vasquez et al. [16] but not quantified. It is also the case of Boegh et al. [21] who tried to propose a bio-similar mucus composition displaying rheological properties (notably in terms of shear-thinning) close to the composition of a mucus isolated from cultured cells. Finally, Tomainolo et al. [24] also described the shear-thinning nature of different native CF mucus samples without proposing any quantification of this property. More generally, the increase in shear-thinning behavior with the polymer concentration, is classical for aqueous polymer solutions. It 
corresponds to an increase in shear-thinning capacity for solutions with a higher macromolecular content due to a concentration enhanced reduction of the flow resistance following the alignment and orientation of polymeric chains in the flow direction as the shear rate increases [17; $23 ; 34]$. Shah et al. [19] compared viscosity curves of respiratory mucus simulants ( 0.5 to $3 \%$ in polyox resin coagulant). However, they only discussed their results in terms of viscosity increase with the coagulant concentration and did not account for the shearthinning nature of the studied fluids, nor for its evolution with the polymer concentration. Kocevar et al. [23] worked on dried porcine gastric mucins solutions at concentrations varying from 10 to $60 \%$ and observed a non quantified shear-thinning behavior for solutions above $30 \%$.

Finally, 3ITTs performed on a $2 \mathrm{wt} \%$ simulant gel (figures $8 \& 9$ ) allow measuring thixotropic recovery times. If the thixotropic nature of native or synthetic mucus has been reported in some of the previous works devoted to mucus rheological characterization $[1 ; 22 ; 23 ; 24]$, it has often not been quantified. Nielsen et al. [22] but also Tomaiuolo et al. [24], described qualitatively the thixotropic nature of native samples observing an hysteresis loop between viscosity curves successively measured at increasing or decreasing shear rates. Kocevar et al. [23] recorded with porcine gastric mucins solutions at concentrations varying from 10 to $60 \%$ the apparent viscosity versus time under a constant shear rate of $50 \mathrm{~s}^{-1}$. They concluded depending on the appearance of a viscosity decrease versus time, that gels above $30 \%$ are thixotropic while lower concentrated one showed no thixotropy. Zahm et al. [1] performed identical measurements on mucus simulants and calculated a thixotropic index based on the stress evolution with time under a $1.6 \mathrm{~s}^{-1}$ shear rate. The thixotropic index was calculated by the ratio of the initial stress value to the plateau stress value and gave values between 1 (no thixotropy) and 1.8 depending on the samples. However, based on our experiments, since two 
different rheometers have been tested here, it seems that the initial stress overshoot height may be dependent on the response time of the rheometer. Indeed, the more precise DHR-2 (TA Instruments) rheometer gave on the same sample a higher stress overshoot than the AR500 rheometer (TA Instruments). As a consequence, thixotropic indexes should not be compared when measured with different apparatus. To the authors' knowledge, 3ITTs results on mucus or mucus simulants have never been published. For comparison purposes however, we can refer to the recent work of Toker et al. [30] describing the results of 3ITTs performed on a mayonnaise or to the work of Mezger [35] in which identical 3ITTs are compared for two different paints. For a $100 \mathrm{~s}^{-1}$ step 2 in both studies, Toker et al. [30] measured a $100 \%$ recovery time varying of 56 to $432 \mathrm{~s}$ for a mayonnaise depending on the temperature, while Mezger [35] measured a $100 \%$ recovery time of $60 \mathrm{~s}$ or $300 \mathrm{~s}$ for the two paint samples (temperature not given). These results indicate that mucus simulants tested here show a slower thixotropic recovery compared to paints or mayonnaises (often used as "model" thixotropic fluids) investigated in these previous works. To conclude with thixotropy, it is obvious that the thixotropic nature of mucus simulants can give rise to much more studies. In particular, it would be interesting to perform an important set of 3ITTs with step 2 covering intermediate shear rate values between $1 \mathrm{~s}^{-1}$ and $100 \mathrm{~s}^{-1}$. Modelling these experiments, a time dependent rheological model for mucus simulants at each active polymer concentration, could then be deduced. Such a time dependent model could be useful to account for the whole rheological complexities of these gels and could for instance allow to simulate their behavior in a model trachea, when submitted to various air pressure signals, such as signals imposed by clearance helping devices. This will be the purpose of a future work.

In conclusion, in this work, a complete and quantified rheological characterization has been performed on mucus simulants at different active polymer concentrations $(0.5 \mathrm{wt} \%$ to $2 \mathrm{wt} \%$ in 
Actigum $^{\mathrm{TM}}$ ). Stress amplitude SAOS sweeps first allowed determining the LVE range of these gels at $20^{\circ} \mathrm{C}$. To account for the end of the LVE range and the subsequent transition towards flow, differents transition stresses (namely, yield $\tau_{\mathrm{y}}$, flow $\tau_{\mathrm{f}}$ and peak $\tau_{\text {peak }}$ stresses) were described. The increase of these transitions stresses with Actigum ${ }^{\mathrm{TM}}$ concentration showed a power law dependence (eq. $2 \& 3$ ). Based on the yield stress value and the corresponding critical deformation, a cohesive volumetric energy $\left(\mathrm{J}^{-3}{ }^{-3}\right)$ that also followed an active concentration increasing power law (eq. 4) was calculated. Elastic and viscous moduli plateau values indicated, for all gel concentrations, stability $\left(\mathrm{G}^{\prime}>\mathrm{G}^{\prime \prime}\right)$, as well as a linear increase with the Actigum ${ }^{\mathrm{TM}}$ concentration. The temperature dependence of the LVE range was not significant in the range between 20 and $37{ }^{\circ} \mathrm{C}$. Frequency SAOS sweeps displayed, only in the case of the lowest active polymer concentration, a low frequency moduli cross-over, showing the liquid-like behavior of this gel under very slow sollicitation and its solid-like behavior under relatively rapid sollicitation. More concentrated gels displayed a solid-like behavior over the whole range of tested frequencies. However, based on the $\tan (\delta)$ evolution one can anticipate a moduli cross-over under lower frequencies as the Actigum $^{\mathrm{TM}}$ concentration increases. In flow mode, to separate viscoplasticity and shear-thinning from thixotropy, steady state flow curves were recorded and the HB model was used to quantify simulants SS viscoplasticity (via a yield stress measured in flow mode $\tau_{0 \mathrm{HB}}$ ) and shearthinning property (via the consistency $(\mathrm{K})$ and flow indexes $(\mathrm{n})$ ). The evolutions of these parameters with the Actigum ${ }^{\mathrm{TM}}$ concentration displayed a power law increase for $\tau_{0 \mathrm{HB}}$ and $\mathrm{K}$ (eq. $6 \& 7$ ) and a linear decrease for $\mathrm{n}$ (eq. 8) indicating an enhanced viscoplasticity and shear-thinning ability for more concentrated gels. Finally the thixotropy of a $2 \mathrm{wt} \%$ gel was tested performing two 3ITTs, submitting the sample to shear rates representative of normal shearing in the lungs $\left(1.6 \mathrm{~s}^{-1}\right)$ or special events such as cough $\left(100 \mathrm{~s}^{-1}\right)$. To quantify thixotropy it was proposed to evaluate a recovery time based on either $90 \%$ or $100 \%$ of recovery of the 
initial structure. Concerning this latter property, further investigations are necessary to fully characterize the thixotropic nature of mucus simulants, in particular to propose a time dependent rheological. This is clearly an interesting prospect for future works.

\section{ACKNOWLEDGMENTS}

The authors are indebted to the PhysioAssist Co. and the Association Nationale de la Recherche et de la Technologie for the CIFRE grant 2014-1287 (O. Lafforgue PhD thesis) and to the Laserson Co. for kindly providing the Actigum ${ }^{\mathrm{TM}}$ and Viscogum ${ }^{\mathrm{TM}}$ polymers. S. Poncet acknowledges also the Canada Foundation for Innovation (John R. Evans Leaders Fund $n^{\circ} 34582$ ) and the Natural Sciences and Engineering Research Council of Canada through the Discovery Grant (RGPIN-2015-06512) for their financial support.

\section{REFERENCES}

[1] Zahm J.M., King M., Duvivier C., Pierrot D., Girod S. and Puchelle E. Role of simulated repetitive coughing in mucus clearance. European Respiratory Journal, 1991, 4(3), p.311-315.

[2] Vasquez P. A. and Forest M. G.. "Complex fluids and soft structures in the human body". Complex Fluids in Biological Systems, Springer Science, S.E. Spagnolie (ed.), New-York, 2015, pp. 53-110.

[3] Thornton D.J. and Sheehan J.K. From mucins to mucus: toward a more coherent understanding of this essential barrier. Proceedings of the American Thoracic Society, 2004, $1(1)$, p.54-61.

[4] Lai S. K., Wang Y-Y., Wirtz D., and Hanes J. Micro- and macrorheology of mucus. Advanced Drug Delivery Reviews 61, 2009, pp. 86-100.

[5] Celli J. P., Turner B. S., Afdhal N. H., Keates S., Ghiran I., Kelly C. P., Ewoldt R. H., McKinley G. H., So P., Erramilli S., Bansil R., and Austin R. H. Helicobacter pylori moves through mucus by reducing mucin viscoelasticity. Proceedings of the National Academy of Sciences of the United States of America, 2009, 106(34):14321.

[6] Taylor C., Pearson J.P., Draget K.I., Dettmar P.W., Smidsrod O., Rheological characterisation of mixed gels of mucin and alginate, Carbohydrate polymers, 2005, 59, 189195.

[7] Riley R.G., Smart J.D., Tsibouklis J., Dettmar P.W., Hampson F., Alf Davis J.,Kelly G., Wilber W.R., An investigation of mucus/polymer synergism using synthessised and characterised poly(acrylic acid)s, International Journal of Pharmaceutics, 2001, 217, 87-100. 
[8] Aubuchon S.R. and Rubin B.K. Application of viscoelastic transformations to rheological analysis of human biological fluids. 1998, New Castle DE: TA Instruments.

[9] Bastholm S. K., Becher N., Stubbe P. R., Chronakis I. S., and Uldbjerg N. The viscoelastic properties of the cervical mucus plug. Acta Obstetricia et Gynecologica Scandinavica, 2014, 93(2):201 - 208.

[10] Hamed R. and Fiegel J. Synthetic tracheal mucus with native rheological and surface tension properties. Journal of biomedical materials research. 2001, Part A, 102(6):1788 1798.

[11] Yuan S., Hollinger M., Lachowicz-Scroggins M. E, Kerr S. C., Dunican E. M., Daniel B. M., Ghosh S., Serpel C Erzurum, Belinda Willard, Stanley L Hazen, Xiaozhu Huang, Stephen D Carrington, Oscarson S., and Fahy J.V. Oxidation increases mucin polymer cross-links to stiffen airway mucus gels. Science Translational Medicine, 2015, 7(276):276ra27.

[12] Taylor Nordgard C. and Draget K. I. Oligosaccharides as modulators of rheology in complex mucous systems Biomacromolecules, 2011, 12(8):3084 - 3090.

[13] Puchelle E., Zahm J.M., Duvivier C., Didelon J., Jacquot J., and Quemada. D. Elastothixotropic properties of bronchial mucus and polymer analogs. i. experimental results.

Biorheology, 1985, volume 22, pages 415 - 423.

[14] Banerjee R., Bellare J.R., Puniyani R.R., Effect of phospholipid mixtures and surfactant formulations on rheology of polymeric gels, simulating mucus, at shear rates experienced in the tracheobronchial tree, Biochemical Engineering Journal, 2001, 7, 195-200.

[15] Lee C.H., Wang Y., Shin S-C., Chien Y.W., Effects of chelating agents on the rheological property of cervical mucus, Contraception, 2002, 65435-440.

[16] Vasquez E. S., Bowser J., Swiderski C., Walters K. B., and Kundu S. Rheological characterization of mammalian lung mucus. RSC Advances, 2014, 4(66):34780.

[17] Bhat P. G., Flanagan D. R., and Donovan M. D. Drug diffusion through cystic fibrotic mucus: steady-state permeation, rheologic properties, and glycoprotein morphology. Journal Of Pharmaceutical Sciences, 1996, 85(6):624 - 630.

[18] Dawson M., Wirtz D., and Hanes J. Enhanced viscoelasticity of human cystic fibrotic sputum correlates with increasing microheterogeneity in particle transport. The Journal of Biological Chemistry, 2003, 278(50):50393 - 50401.

[19] Shah S., Fung K., Brim S. and Rubin B.K., An in vitro evaluation of the effectiveness of endotracheal suction catheters, Chest, 2005, 128 (5), p.3699-3704.

[20] Celli J. P.,. Turner B. S, Afdhal N. H.,. Ewoldt R. H, Mckinley G. H., Rama Bansil, and Erramilli S. Rheology of gastric mucin exhibits a ph-dependent sol-gel transition, Biomacromolecules, 2001, 8(5):1580 - 1586.

[21] Boegh M., Baldursdóttir S. G, Nielsen M. H., Müllertz A., and Nielsen H. M. developement and rheological pofiling of biosimilar mucus. Annual transaction of th enordic rheology society, 2013, vol 11, 233-240. 
[22] Nielsen H., Hvidt S., Sheils C.A. and Janmey P.A. Elastic contributions dominate the viscoelastic properties of sputum from cystic fibrosis patients. Biophysical Chemistry, 2004, 112, p.193-200.

[23] Kocevar-Nared J., Kristl J., Smid-Korbar J., Comparative rheological investigation of crude gastric mucin and natural gastric mucus, Biomaterials, 1997, 18, 677-681.

[24] Tomaiuolo G., Rusciano G., Caserta S., Carciati A., Carnovale V., Abete P., Sasso A., and Guido S. A new method to improve the clinical evaluation of cystic fibrosis patients by mucus viscoelastic properties. Plos One, 2014, 9(1):e82297.

[25] Coussot P and Ancey C. Rheophysical classification of concentrated suspensions and granular pastes. The American Physical Society 1999;59:4445-57.

[26] NiraulaB., King T.C., Misran M., Evaluation of rheological property of dodecyl maltoside, sucrose dodecanoate, Brij 35p and SDS stabilizided O/W emulsion: effect of head group stracture on rheology property and emulsion stability, colloides and Surfaces A., 2004, 251, 59-74.

[27] Mezger T.G.. The Rheology Handbook: For Users of Rotational and Oscillatory Rheometers. European Coatings. Vincentz Network, 2014.

[28] Hyun K., Kim S.H., Ahn K.H., Lee S.J., "Large amplitude oscillatory shear as a way to classify the complex fluids", J. Non-Newtonian Fluid Mech., 2002, 107, pp. 51-65.

[29] Coussot P., and Grossiord J-L., Comprendre la rhéologie de la circulation du sang à la prise du béton, EDP sciences, 2001.

[30] Toker O.S., Karusa S., Yilmaz M.T., Karaman S., 3ITT in food applications: a novel technique to determine structural regeneration of mayonnaise under different shear conditions, Food research International, 2015, 70, 125-133.

[31] Hyun K., Wilhelm M., Klein C. O., Cho K. S., Nam J. G., Ahn K. H., Lee S. J., Ewoldt R. H., and McKinley G. H., A review of nonlinear oscillatory shear tests: Analysis and application of large amplitude oscillatory shear (laos). Progress in Polymer Science, 2011, 36, pp. 1697-1753.

[32] Mori M., Seyssiecq I., Roche N., Rheological measurements of sewage sludge forvarious solids sonsentrations and geometry, Process Biochemsitry, 2006, 41, 1656-1662.

[33] Seyssiecq Guarente I., Poncet S. Etude sur la caractérisation rhéologique du mucus bronchique. Premiers résultats sur fluides modèles. rapport confidentiel, 2012.

[34]. Malkin A.Ya., Non-Newtonian viscosity in steady state shear flows, J. Non-Newtonian Fluid Mechanics, 2013, 192, 48-65.

[35] Mezger T.G., applied rheology Anton Paar GmbH, 2015. 


\section{FIGURE LEGENDS}

Figure 1: SAOS sweeps for a $1.5 \mathrm{wt} \%$ sample. (a) Stress sweep $\left(\frac{1}{2 \pi} \mathrm{Hz}\right)$ (b) Frequency sweep (1Pa).

Figure 2 : Evolution of $G^{\prime}(a), G^{\prime \prime}(b), \tan (\delta)(c)$ vs stress amplitude for different Actigum $^{\mathrm{TM}}$ concentrations

Figure 3: (a) Limit stresses for LVE range \& $E_{c}$ (b) $G^{\prime} \& G^{\prime \prime}$ plateau values vs. Actigum ${ }^{\mathrm{TM}}$ concentration

Figure 4: Evolution of $\mathrm{G}^{\prime}$ and $\mathrm{G}^{\prime \prime}$ vs. stress amplitude at either $20^{\circ} \mathrm{C}$ or $37^{\circ} \mathrm{C}$ for a $0.75 \mathrm{wt} \%$ gel at $\frac{1}{2 \pi} \mathrm{Hz}$

Figure 5: Evolution of $\mathrm{G}^{\prime}(\mathrm{a}), \mathrm{G}^{\prime \prime}(\mathrm{b})$ and $\tan (\delta)$ (c) vs frequency for different Actigum $^{\mathrm{TM}}$ concentrations

Figure 6: SS rheogram of a $2 \mathrm{wt} \%$ simulant

Figure 7: HB model parameters vs. Actigum ${ }^{\mathrm{TM}}$ concentration

Figure 8: 3ITT step 1 at $0.029 \mathrm{~s}^{-1}$, step 2 at $1.6 \mathrm{~s}^{-1}$, step 3 at $0.029 \mathrm{~s}^{-1}$

Figure 9: 3ITT step 1 at $0.029 \mathrm{~s}^{-1}$, step 2 at $100 \mathrm{~s}^{-1}$, step 3 at $0.029 \mathrm{~s}^{-1}$ 


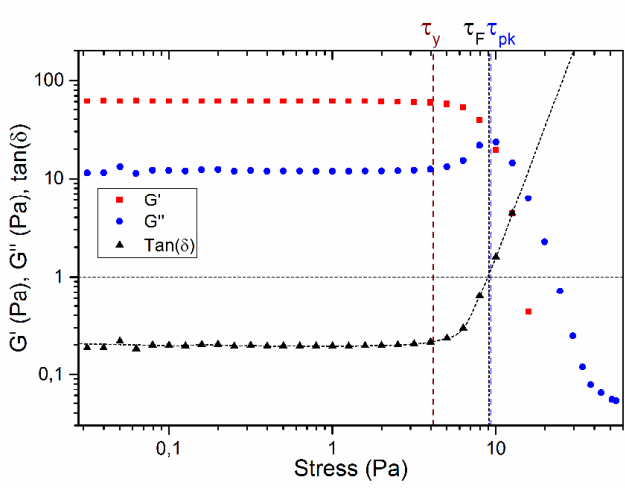

(a)

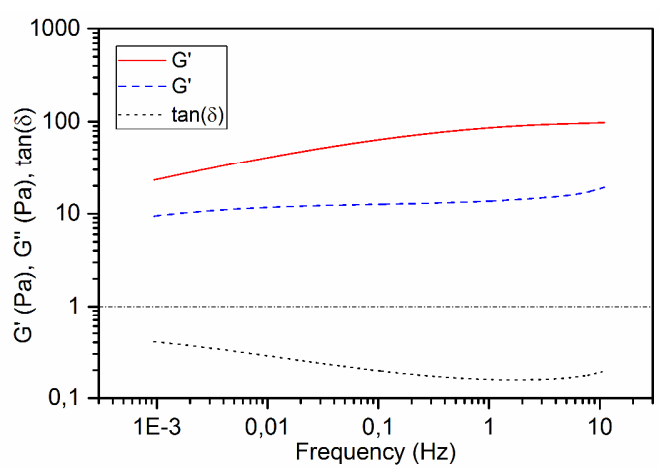

(b)

Figure 1. 

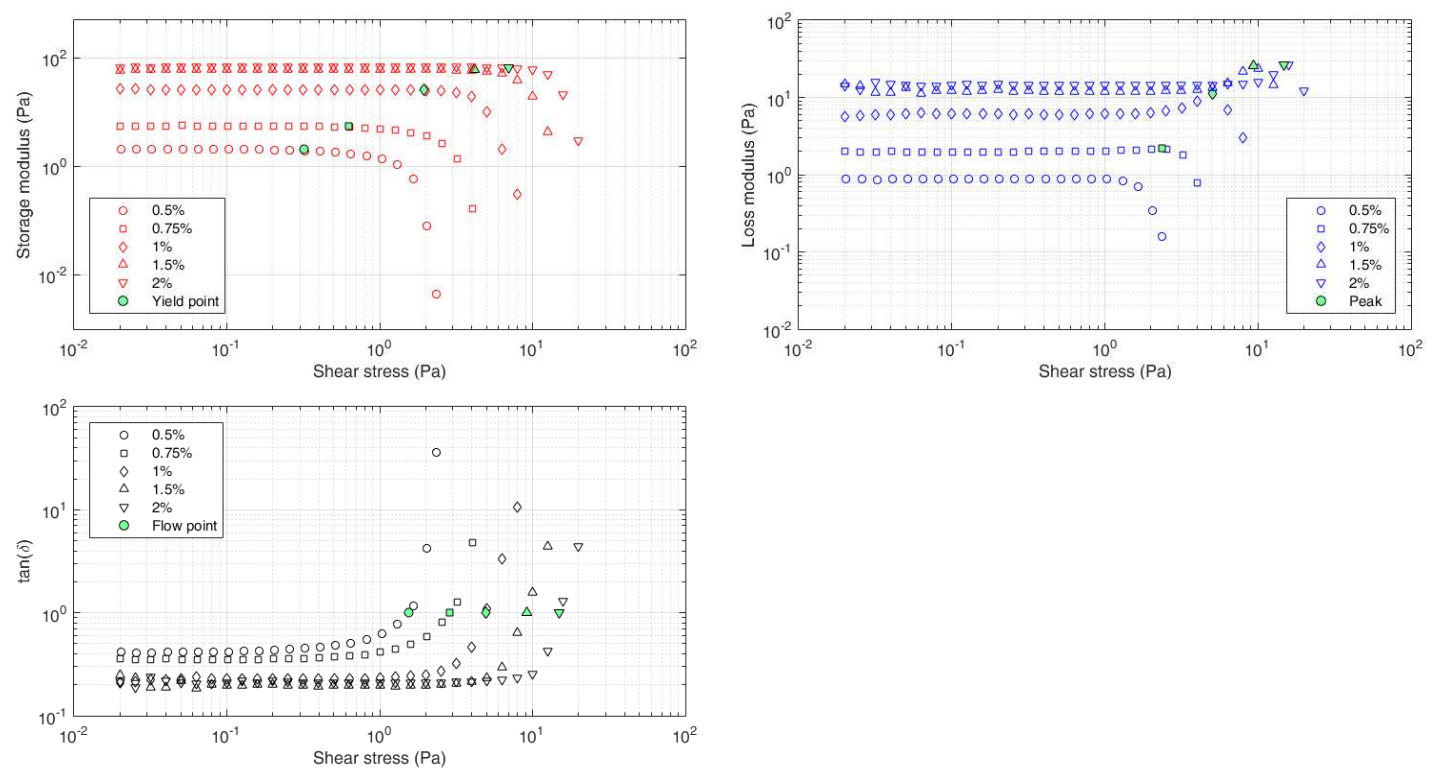

Figure 2 

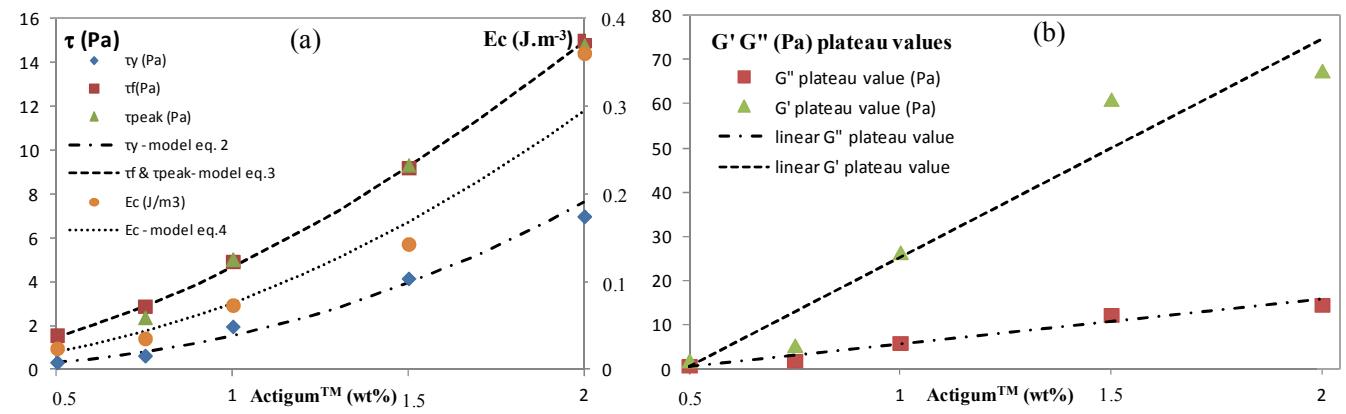

Figure 3 


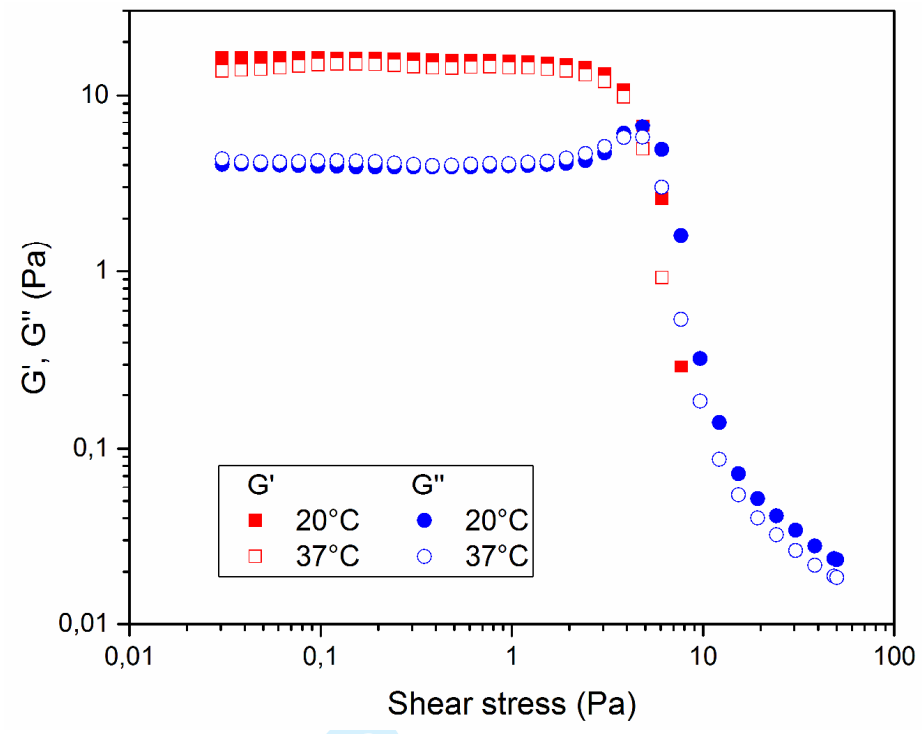

Figure 4 


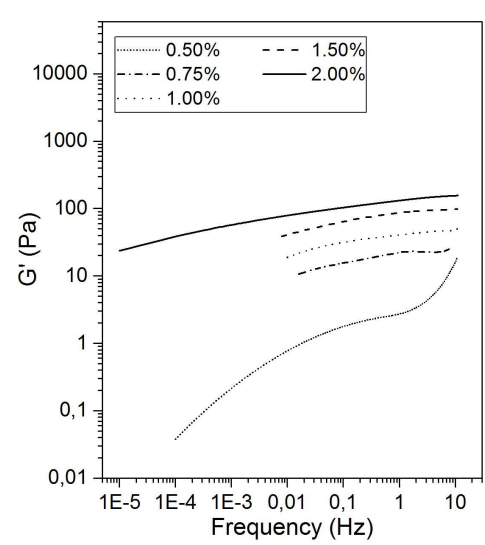

(a)

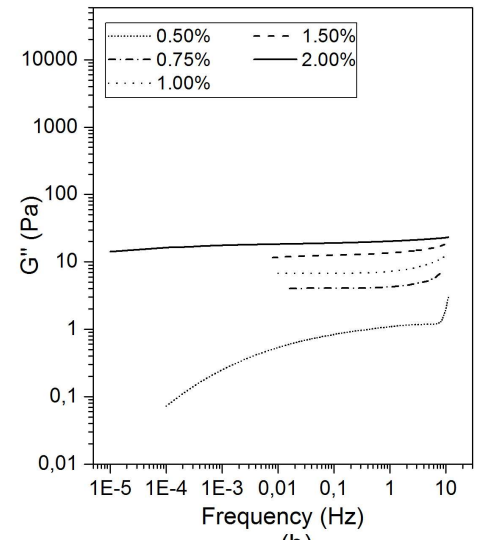

(b)

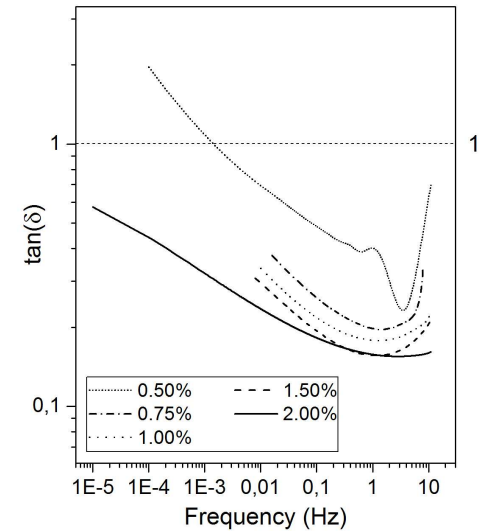

(c)

Figure 5 


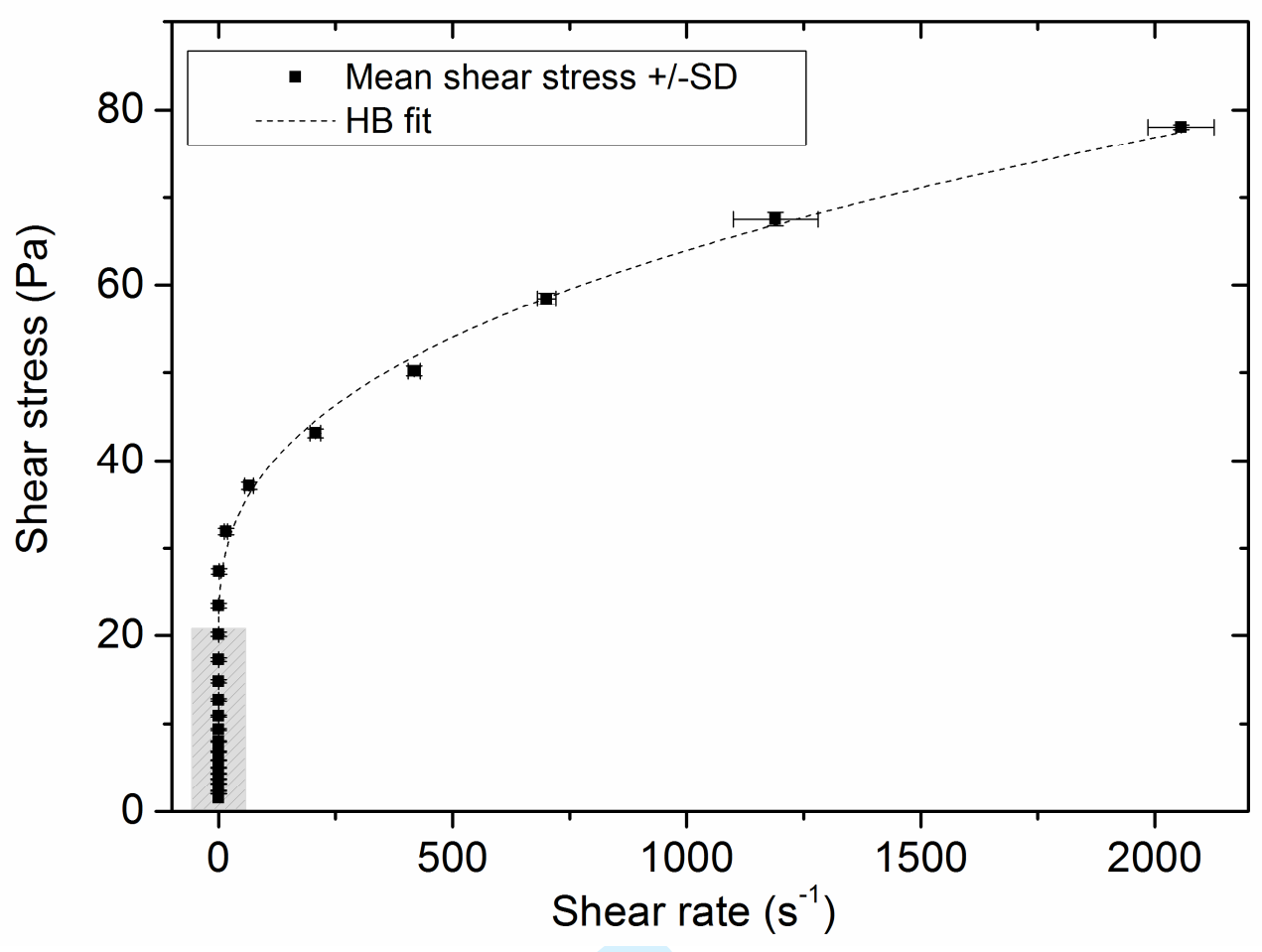

Figure 6: SS rheogram of a $2 \mathrm{wt} \%$ simulant 


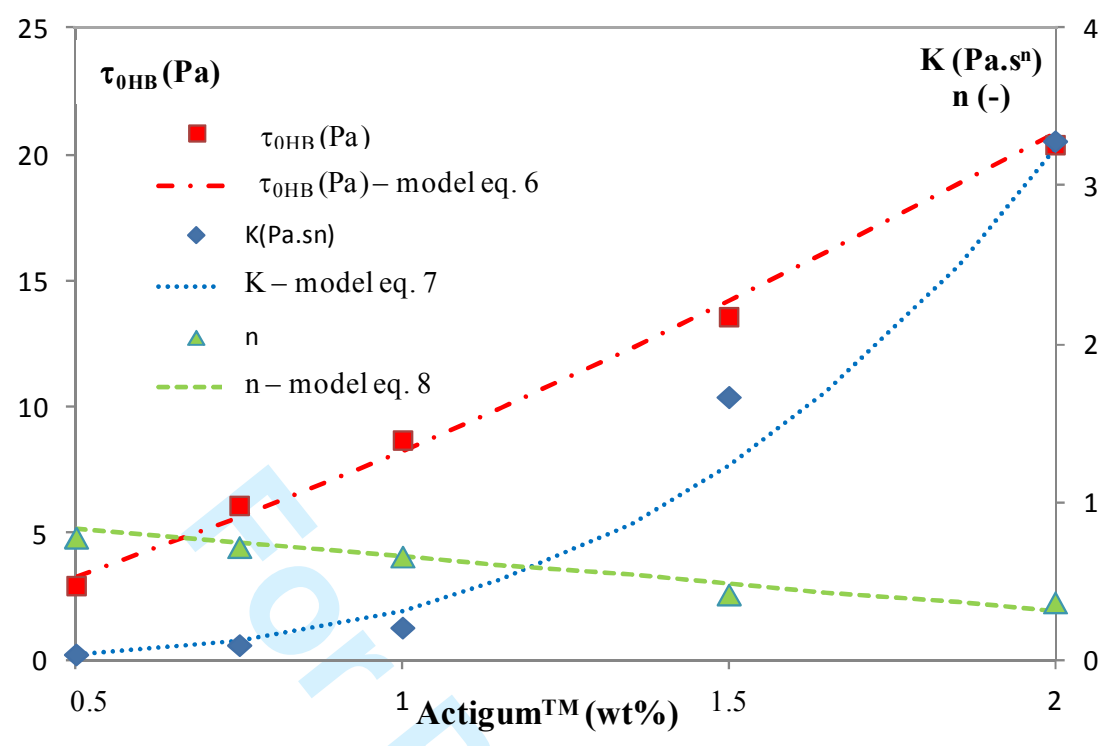

Figure 7 


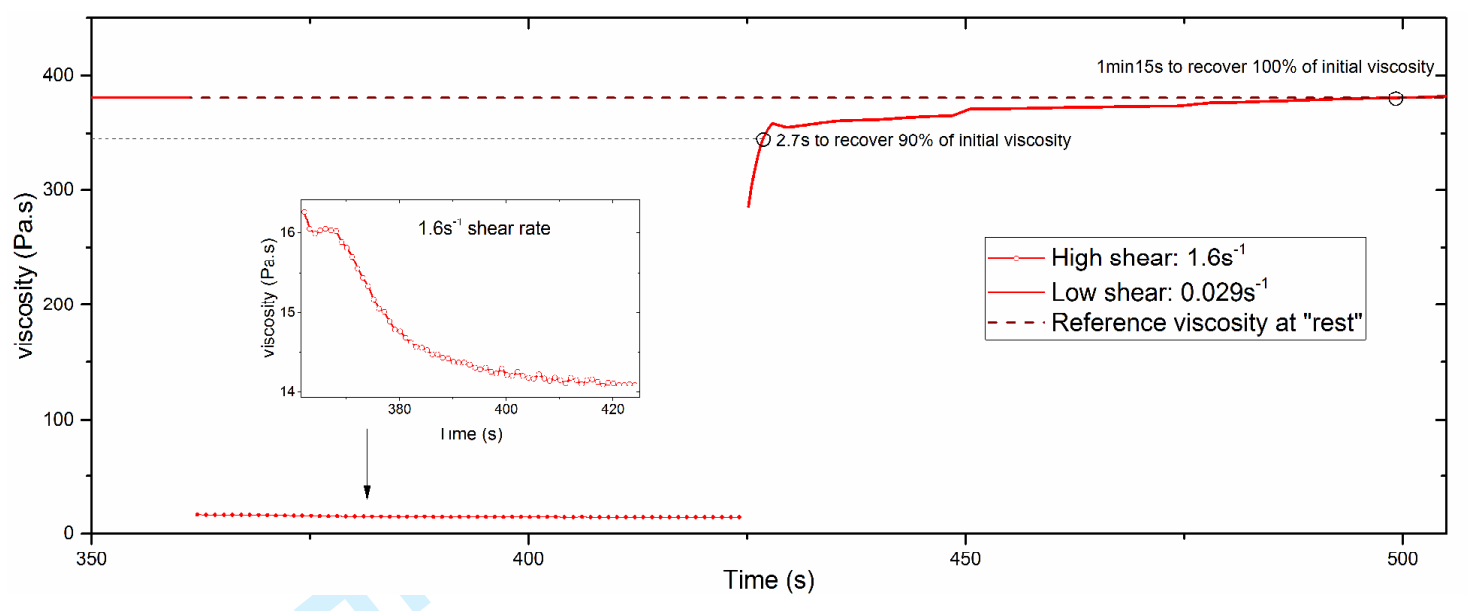

Figure 8 


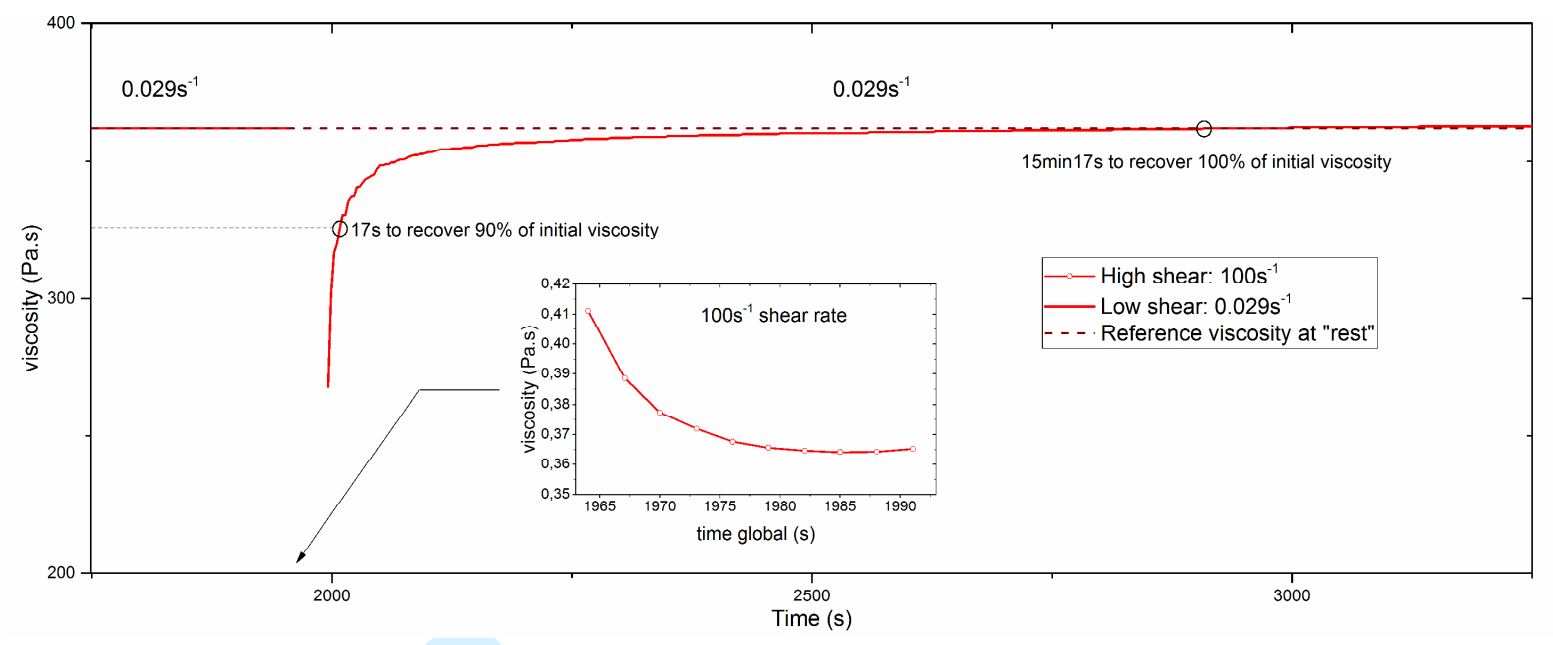

Figure 9 
Table 1. Evolution of limit stresses for LVE range, $E_{c}$ and moduli plateau values vs active polymer concentrations.

\begin{tabular}{|ccccccc}
\hline [Actigum $\left.^{\mathrm{TM}}\right](\mathbf{w t} \%)$ & $\tau_{\mathrm{y}_{-}}(\mathrm{Pa})$ & $\tau_{\mathrm{f}_{-}}(\mathrm{Pa})$ & $\tau_{\text {peak }}(\mathrm{Pa})$ & $\mathrm{E}_{\mathrm{c}}\left(\mathrm{J} . \mathrm{m}^{-3}\right)$ & $\mathrm{G}^{\prime}(\mathrm{Pa})$ & $\mathrm{G}^{\prime \prime}(\mathrm{Pa})$ \\
\hline 0.50 & 0.32 & 1.55 & - & 0.024 & 2.07 & 0.88 \\
0.75 & 0.63 & 2.88 & 2.37 & 0.035 & 5.52 & 2.02 \\
1 & 1.96 & 4.92 & 5.02 & 0.073 & 26.56 & 6.06 \\
1.50 & 4.15 & 9.20 & 9.32 & 0.143 & 61.18 & 12.34 \\
2.00 & 6.98 & 15.00 & 14.78 & 0.360 & 67.64 & 14.66 \\
\hline
\end{tabular}


Table 2. Evolution of the HB model parameters vs. active polymer concentrations.

\begin{tabular}{cccc}
\hline Actigum $\left.^{\text {TM }}\right](\mathbf{w t} \%)$ & $\tau_{\text {онв }}(\mathbf{P a})$ & $\mathbf{K}\left(\mathbf{P a . s}^{\mathbf{n}}\right)$ & $\mathbf{n}$ \\
\hline 0.50 & 2.98 & 0.04 & 0.78 \\
0.75 & 6.15 & 0.1 & 0.72 \\
1 & 8.74 & 0.21 & 0.66 \\
1.50 & 13.62 & 1.67 & 0.42 \\
2.00 & 20.43 & 3.29 & 0.37 \\
\hline
\end{tabular}

